\title{
PENERAPAN ADVANCE ORGANIZER DENGAN MODEL PEMBELAJARAN EKSPOSITORI BERPOLA LESSON STUDY UNTUK MENINGKATKAN HASIL BELAJAR FISIKA PESERTA DIDIK
}

\author{
Ahmad Harjono*, I Wayan Gunada, Sutrio, Hikmawati \\ Program Studi Pendidikan Fisika, Universitas Mataram \\ *Email: harjono.fkip@unram.ac.id
}

\begin{abstract}
This study aims to improve the quality of learning through the implementation of lesson study $(L S)$ with expository learning model assisted advance organizer to improve activity and learning outcomes. Implementation of $L S$ is done in SMA Negeri 3 Mataram by taking X class MIA3 and considered appropriate. $L S$ is executed in two action cycles with stages plan, do (implementation and observation), and see (reflection). The research data are qualitative and quantitative data. Qualitative data are derived from important notes of planning and implementation phases and instructional sheet of instructional learning, student activity, and teacher activity, as well as the reflection stage. Quantitative data are analyzed to see improvements in learning outcomes. Implementation of lesson study through expository model assisted by advace organizer can improve physics learning result of class X student of MIA3 SMAN 3 Mataram. The average score of student activity increases from 22.17 with active category in cycle I to 28.85 with very active category in cycle II. Increased classical completeness achievement $70 \%$ cycle I to $91 \%$ in cycle II.
\end{abstract}

Keywords: advance organizer, expository learning, lesson study

\section{PENDAHULUAN}

Berbagai upaya dilakukan untuk meningkatkan kualitas pembelajaran dengan tujuan untuk meningkatkan hasil belajar peserta didik. Salah satu pendekatan sistem yang dilakukan adalah dengan mengadaptasi sistem yang telah dilakukan di Negara Jepang, yaitu Lesson Study. Konsep dan praktek lesson study (LS) pertama kali dilaksanakan di Jepang oleh para guru pendidikan dasar yang terkenal dengan nama kenkyuu jugyo. Orang berjasa mengembangkan LS adalah Makoto Yoshida. Kesuksesan Jepang dalam mengembangkan pembelajaran dengan prinsip LS, diikuti beberapa negara termasuk Amerika Serikat yang dipelopori oleh Chaterine Lewis yang aktif melakukan penelitian sejak tahun 1983. Saat ini, Indonesia juga telah melaksanakan praktek LS, dari pendidikan dasar hingga pendidikan tinggi.

Pembelajaran konvensional tidak optimal memberikan harapan dan sumbungan signifikan terhadap peningkatan mutu proses dan hasil belajar peserta didik, sehingga dibutuhkan cara untuk mengubah praktek pembelajaran dari yang berpusat guru (teacher-centered) menjadi berpusat peserta didik (student-centered). Salah satu alternatif yang dapat mendorong perubahan paradigma pembelajaran tersebut adalah dengan pola lesson study.

LS bukanlah metode atau strategi pembelajaran, tetapi merupakan salah satu upaya untuk pembinaan pada sekelompok guru untuk meningkatkan kualitas proses pembelajaran, dilakukan secara kolaboratis, dan terus-menerus melalui kegiatan perencanaan, pelaksanaan, pengamatan, refleksi, dan pelaporan dari hasil pembelajaran. LS bukanlah kegiatan sesaat, tetapi merupakan kegiatan berkelanjutan, tiada henti, bersifat kolabratif sebagai upaya menerapkan prinsip-prinsip total quality management, yakni memperbaiki proses dan hasil pembelajaran peserta didik secara berkelanjutan. LS memiliki harapan bahwa akan terbentuk masyarakat pembelajar (learning society) yang secara ajeg dan melembaga memperbaiki diri. Sementara 
itu, Lewis (2004) menyebutkan bahwa: "lesson study is a simple idea. If you want to improve instruction, what could be moreobvious than collaborating with fellow teachers to plan, observe, and reflect onlessons? While it may be a simple idea, lesson study is a complex process, supported bycollaborative goal setting, careful data collection on student learning, and protocols that enable productive discussion of difficult issues".

Implementasi LS di Indonesia telah diintegrasikan dalam program pemerintah pusat, yakni Program Induksi Guru Pemula (PIGP). Dalam Permendiknas No. 27 Tahun 2010, PIGP merupakan program pemerintah pusat untuk mempercepat keprofesionalan guru pemula. PIGP dikembangkan dan dilaksanakan dengan menggunakan pendekatan LS. Hal serupa semestinya dapat dilakukan untuk mempercepat keprofesional dosen-dosen baru di Perguruan Tinggi. Untuk itu diperlukan suatu program yang dapat menginisiasi lembaga pendidikan tinggi untuk belajar mengembangkan LS sebagai sarana mengingkatkan mutu layanan perkuliahan (Widarto, 2014).

Secara umum tahapan-tahapan LS adalah: (1) perencanaan (plan); pelaksanaan (do) dan (3) refleksi (see). Tahap perencanaan; para guru atau dosen berkolabari untuk merencanakan RPP yang berorientasi kepada peserta didik. Analisis terhadap kebutuhan dan masalah pembelajaran yang akan dihadapi perlu didiskusikan bersama, terutama terkait dengan kompetensi dasar, bagaimana membelajarkan materi yang sesuai dengan karakteriktik peserta didik, kesiapan sarana dan fasilitas, sehingga pada saat melaksanakan pembelajaran dapat berlangsung efektif dan sesuai dengan harapan dan rencana yang telah disusun. Berbagai permasalahan seyogyanya dapat diantisipasi pada saat perencanaan atau penyiapan RPP sehingga pada saat pelaksanaan, yakni dari tahap pendahuluan, inti, dan akhir atau penutup pembelajaran berjalan efektif. Tahap pelaksanaan, sesuai dengan kesepakatan dosen atau guru model yang memraktekkan RPP yang telah disepakati dan kegiatan pengamatan (observasi) oleh pengamat. Beberapa hal yang perlu diperhatikan pada saat pembelajaran adalah pengamat tidak diperkenankan mengganggu kegiatan pembelajaran, berbicara dengan sesama pengamat, bertanya kepada peserta didik. Hasil pencatatan oleh pengamat sesuai dengan RPP dan kesepakatan saat merencanakan RPP. Tahap refleksi, diperlukan untuk mengevaluasi pelaksanaan pembelajaran untuk memperbaiki proses pembelajaran berdasarkan hasil pengamatan. Pada tahap ini, diskusi berbagai hal terkait dengan pelaksanaan LS dipimpin oleh seseorang dari komunitas yang telah disepakati sebelumnya. Guru atau dosen model diberikan kesempatan pertama untuk menyampaikan kesan-kesan atau perasaan dan tanggapan tentang praktek pembelajaran yang telah dilakukan terutama bagaimana melaksanakan RPP. Selanjutnya, pengamat menyampaikan kesan dan saran yang konstruktif berdasarkan hasil pengamatan bukan berdasarkan opini pribadi.

Pemilihan model atau metode yang tepat dalam pengkajian pasti dilakukan pada kegiatan lesson study dalam merancang RPP, dengan memperhatian isi materi, peserta didik, cakupan waktu, media atau alat bantu lainnya. Pemilihan model pembelajaran yang sesuai akan memudahkan guru mengajar dan meningkatkan interaksi guru, peserta didik, dan media. Salah satu model pembelajaran yang lazim digunakan guru dalam mengajar adalah model pembelajaran ekspositori. Heinich, et al., (2002) menyebutkan tahaptahap model pembelajaran ekspositori sebagai berikut: (1) tahap pendahuluan, guru menyampaikan kompetensi dan tujuan 
pembelajaran, memberikan motivasi, peserta didik mendengarkan, dan mencatat hal-hal yang dianggap penting; (2) tahap penyajian materi, guru menyampaikan materi pembelajaran dengan ceramah dan tanya jawab, (3) tahap latihan terbimbing, (4) tahap latihan mandiri, (5) tahap penutup dan evaluasi, serta mengadakan kegiatan tindak lanjut berupa penugasan dalam rangka pendalaman materi, dan bersama peserta didik merangkum materi pembelajaran. Selanjutnya, Ausbel (1960) menawarkan belajar penerimaan verbal bermakna ((meaningful verbal reception) untuk dapat memanfaatkan model pembelajaran ekspositori dengan menghadirkan konsep-konsep yang terhubungkan dengan struktur kognitif peserta didik. Gagasan ini untuk mengaitkan konsep lama dan konsep baru adaalah untuk mendapatkan pembelajaran bermakna (meaningful learning).

Pembelajaran bermakna dapat difasilitasi dengan menggunakan advance organizer. Ausubel dalam Harjono (2013) menyatakan bahwa cara yang paling efektif untuk menghubungkan materi yang telah dipelajari dan tersimpan dalam struktur kognitif dengan materi baru atau konsepkonsep yang akan dipelajari dengan memanfaatkan advance organizer (AO). AO membantu peserta didik mencari konsepkonsep yang relevan dalam struktur kognitif selanjutnya dipadukan dengan materi baru untuk meningkatkan pemahaman terhadap isi materi. Salah satu bentuk AO adalah peta konsep. Peta konsep adalah alat grafis untuk mengorganisasi dan menampilkan pengatahuan. Peta konsep biasanya berbentuk melingkar atau kotak dan hubungan antara konsep diperlihatkan oleh garis penghubung dua konsep (Novak dan Canas, 2008).

$A O$ dapat membantu peserta didik mencari konsep yang relevan dalam struktur kognitifnya supaya dapat dipadukan dengan konsep yang ada dalam materi baru untuk meningkatkan pemahaman terhadap isi materi yang dipelajari. $A O$ adalah introductory material at a higher level of abstraction, generality, and inclusiveness than the learning task itself (Ausubel, 1978).

Ausubel dalam Arends (1997), menganalogikan $A O$ sebagai jembatan yang menghubungkan antara pengetahuan awal dengan pengetahuan baru. Saran yang diberikan, sebaiknya materi pada $A O$ menonjolkan ide-ide utama.Advance organizer dapat berbentuk penjelasan verbal, wacana teks, gambar, atau diagram.

Ausubel (1978) dan Novak (1977) mengunakan dua prinsip dalam pengorganisasian isi materi pengajaran secara efisien semua bidang pengetahuan, yaitu progressive differentiation dan integrative reconciliation. Diferensiasi progresifyang berarti bahwa pengertian yang utama dari suatu disiplin ilmu diberikan dahulu, diikuti oleh materi yang berangsurangsur bertambah khusus atau rinci, dan prinsip rekonsiliasi integratif, berarti bahwa pengertian-pengertian baru harus dengan sengaja dikaitkan dengan materi yang sudah dipelajari. Progressive differentiation diterapkan dengan advance organizer dan berfungsi untuk memperkuat struktur kognitif dan retensi dari informasi yang diterima (Diptoadi, 1990). Integrative reconciliation diterapkan dalam post organizer atau ikhtisar akhir (Reigeluth dan Stein, 1983) dan sebagai pernyataan akhir pembelajaran yang berisi ide-ide pokok mata pelajaran. Bila isi materi bidang studi telah dipertimbangkan dan disusun secara diferensiasi progresif, dengan sendirinya diikuti oleh rekonsiliasi integratif, meskipun diperlukan kerjasama aktif dari peserta didik. Lambat laun akibat dari prinsip itu, peserta didik menguasai disiplin ilmu tersebut. Perlu diingat bahwa baik disiplin ilmu maupun urutan pembelajaran dibangun 
dari atas ke bawah dengan konsep-konsep khusus, prinsip, dan proposisi.

Terdapat dua macam $A O$, yaitu expository dan comparation. Expository organizer mengandung konsep dasar pada tingkat abstraksi tinggi dan mungkin beberapa konsep di bawahnya. Konsepkonsep tersebut berfungsi sebagai perantara untuk mengaitkan informasi baru, sedangkan comparative organizer banyak digunakan pada materi yang relatif telah dikenal. Tujuan dari advance organizer disusun untuk membedakan konsep lama dengan konsep yang baru, untuk mencegah kerancuan akibat dari persamaannya (Medsker \& Holdsworth, 2001, Marzano, et al., 2000).

Mayer (1979) menggambarkan karakteristik dasar sebuah $A O$ sebagai berikut.

(a) short set of vocal or visual information, (b) presented prior to learning a larger body of tobe-learned information, (c) containing no specific content from the to-be-learned information, (d) providing a means of generating the logical relationships among the elements in the to-be learned information, and (e) influence the learning and encoding process.

Ausubel (1968) menyatakan pula bahwa $A O$ tidak sama dengan ringkasan atau overviews, yang berisi teks pada tingkat yang sama dari abstraksi sebagaimana materi pembelajaran, tetapi dirancang untuk menjembati kesenjangan antara yang sudah diketahui dan yang akan dipelajari agar berhasil dalam belajar. $A O$ adalah informasi pengetahuan atau materi pengantar yang dipresentasikan di awal pembelajaran, juga merupakan strategi pembelajaran sehingga memiliki sintaks atau fase aktivitas dalam pembelajaran.
Menurut Joyce, et al., (2000), Medsker dan Holdsworth (2001), dan Downing (1994), AO mempunyai tiga fase aktivitas, yaitu:Fase I (includes presentation of advance organizer), Fase II (includes making links to/from the organizer), dan Fase III (strengthening of cognitive organization)

Secara singkat sintaks $A O$ terdiri dari tiga fase kegiatan. Fase pertama, presentasi pengorganisasi awal, fase kedua ialah presentasi tugas/materi pembelajaran, dan fase ketiga ialah penguatan organisasi kognitif dan menelaah hubungan antara materi pembelajaran dengan pengetahuan yang sudah ada agar terjadi proses belajar secara aktif. Berdasarkan pandangan Ausubel dan Novak terhadap belajar penerimaan aktif (active reception learning), $A O$, struktur kognitif, dan materi pelajaran atau bidang studi untuk memperoleh pembelajaran bermakna (meaningful learning), maka perlu dirancang suatu strategi pembelajaran yang sesuai dengan tujuan pembelajaran. $A O$ berfungsi sebagai materi pengantar untuk menjembatani pengetahuan yang telah diketahui sebelumnya dengan materi yang akan dipelajari yang memiliki sifat-sifat tingkat abstraksi tinggi, umum, dan inklusif. $A O$ dipresentasikan pada fase pertama, presentasi materi dengan memilih metode atau strategi pembelajaran tertentu pada fase kedua, dan memperkuat organisasi kognitif pada fase ketiga.

Dalam konteks pembelajaran, ekspositori merupakan strategi yang dilakukan guru untuk mengatakan atau menjelaskan fakta-fakta, gagasan-gagasan, dan informasi-informasi penting lain kepada para peserta didik (Jarolimek dan Foster, 1981).

Menurut Romiszowski (1984), strategi pembelajaran ekspositori berlangsung melalui beberapa tahap sebagai berikut: pertama, penyajian informasi. 
Penyajian informasi ini dapat dilakukan dengan ceramah, latihan, atau demonstrasi; kedua, tes penguasaan dan penyajian ulang bila dipandang perlu; ketiga, memberikan kesempatan penerapan dalam bentuk contoh dan soal, dengan jumlah dan tingkat kesulitan yang bertambah; dan keempat, memberikan kesempatan penerapan informasi baru dalam situasi dan masalah sebenarnya. Menurut Heinich, et al, (2002), strategi pembelajaran ekspositori adalah cara pengajaran dengan langkah-langkah: (1) menyajikan informasi, (2) memberikan contoh, dan (3) mengevaluasi pengetahuan yang telah diinformasikan kepada peserta didik. Sedangkan, Hunter (1984) secara ringkas memberikan prosedur pembelajaran ekspositori dengan langkah-langkah sebagai berikut: (1) pendahuluan, (2) tujuan dan maksud, (3) input pembelajaran, (4) latihan terbimbing, (5) penutup, dan (6) latihan mandiri.

Jacobson, et al, (1989) menyatakan bahwa strategi pembelajaran ekspositori merupakan proses pembelajaran yang lebih berpusat pada guru (teacher centered), guru menjadi sumber dan pemberi informasi utama, menerangkan konsep, mendemonstrasikan keterampilan dalam memperoleh pola, aturan, dalil, memberi contoh dan penyelesaian, dan memberikan kesempatan bertanya.

Sagala (2006) menyatakan bahwa pembelajaran ekspositori menyajikan materi pelajaran secara utuh atau menyeluruh, lengkap dan sistematis dengan penyampaian verbal. Strategi ini sering disebut metode ceramah atau konvensional. Ausubel (1963) menyatakan pula bahwa kebanyakan guru menyukai metode pembelajaran ini. Pembelajaran ekspositori adalah cara yang efisien dan efektif untuk mengorganisasi pembelajaran di kelas. Dalam strategi pembelajaran ekspositori, media seperti video pendidikan dan alat bantu visual digunakan untuk mendukung penjelasan.
Alat bantu visual dalam strategi pembelajaran ekspositori antara lain; contoh-contoh fisik, gambar-gambar, diagram, dan peta. Penambahan penjelasan verbal dengan alat bantu visual akan meningkatkan efektivitas penyimpanan informasi dalam memori jangka panjang dan mendapatkannya kembali.

Penelitian ini menggunakan sintaks strategi pembelajaran ekspositori yang diadaptasi dari Romiszowski (1984), Heinich, et al., (2002), dan Hunter (1984) dengan tahap-tahap sebagai berikut: (1) tahap pendahuluan, guru menyampaikan kompetensi dan tujuan pembelajaran, memberikan motivasi, peserta didik mendengarkan, dan mencatat hal-hal yang dianggap penting; (2) tahap penyajian materi, guru menyampaikan materi pembelajaran dengan ceramah dan tanya jawab, (3) tahap latihan terbimbing, (4) tahap latihan mandiri, (5) tahap penutup dan evaluasi, serta mengadakan kegiatan tindak lanjut berupa penugasan dalam rangka pendalaman materi, dan bersama peserta didik merangkum materi pembelajaran. Presentasi $A O$ sebelum tahap-tahap sintaks strategi pembelajaran ekspositori.

\section{METODE PENELITIAN}

Tempat penelitian adalah SMA Negeri 3 Kota Mataram dengan jangka waktu penelitian dari bulan April-Desember 2017.

Subjek penelitian adalah peserta didik kelas X SMA Negeri 3 Kota Mataram yang mendapat matapelajaran fisika. Ada seorang guru matapelajaran fisika menjadi guru model dan beberapa lainnya menjadi pengamat (observer).

Jenis penelitian adalah semacam penelitian tindakan kelas (classaction research) dengan serangkaian tahapan: (1) Sosialisasi dan workshop tentang lesson study kepada guru fisika, (2) Observasi atau pengamatan pembelajaran kepada salah 
seorang guru (calon guru model), (3) Penyusunan perangkat pembelajaran dan alat observasi (plan), (4) Pelaksanaan dan observasi pembelajaran (do) atau open lesson, (5) refreksi (see), dan evaluasi pembelajaran. Secara keseluruhan penelitian berlangsung dalam tiga siklus, sesuai dengan model Lewis (2002).

Instrumen penenelitian berupa perangkat pembelajaran (RPP, LKPD, lembar obsevasi aktivitas guru dan peserta didik, dan lembar observasi keterlaksanaan pembelajaran), instrumen tes hasil belajar, dan alat perekam pembelajaran.

Data penelitian diperoleh dari instrumen penelitian, rekaman hasil KBM, dan hasil diskusi atau refleksi dengan para pengamat. Hasil diskusi menjadi bahan untuk memperbaiki proses pembelajaran.

Data hasil observasi dianalisis secara deskriptif untuk mengetahui kualitas proses pembelajaran dan kemajuan hasil belajar fisika tiap siklusnya

\section{HASIL DAN PEMBAHASAN Siklus I}

Tahap plan (perencanaan), guru model banyak mendapatkan masukan tentang penyusunan peta konsep agar dapat menjembatani pengalaman belajar atau pengetahuan terdahulu dengan pengetahuan yang akan dipelajari. Peta konsep seyogyanya juga disusun dari konsepkonsep yang khusus berproposisi dengan konsep-konsep yang lebih umum agar fungsi peta konsep sebagai $A O$ efektif dalam pembelajaran. Peta konsep juga disarankan dirancang setiap pertemuan. Pemberian penguatan dan penghargaan juga menjadi perhatian agar peserta didk paling tidak ada pada bagian akhir presentasi kinerja individu atau kelompok. Tujuan pembelajaran harus menggunakan kata kerja operasional atau dapat diukur. Selain itu, pemanfaatan LKPD harus secara eksplisit tercantum dalam inti pembelajaran.
Tahap do (pelaksanaan), guru model mampu melaksanakan pembelajaran dengan baik sehingga peserta didik terlibat aktif dan respon positif dari mereka terhadap pembelajaran.

Tahap see (refleksi), guru model banyak mendapat masukan agar pembelajaran pada siklus kedua dapat berlangsung lebih efektif dan mampu meningkatkan aktivitas dan hasil belajar peserta didik.

\section{Siklus II}

Tahap plan dimanfaatkan oleh guru model, sejawat dan pembimbing untuk memperbaiki RPP, peta konsep sebagai $A O$, dan LKPD seseuai saran pada saat refleksi.

Tahap do, guru model mampu lebih baik melaksanakan pembelajaran terlihat dari aktivitas dan interaksi antar peserta didik maupun dengan guru.

Tahap see, guru model menunjukkan kepuasannya lebih baik dan dapat mengendalikan pembelajaran.

Secara umum keterlaksanan pembelajaran oleh guru model dalam melaksanakan RPP mengalami peningkatan pada siklus pertama sebesar 3,54 (baik) dan siklus kedua sebesar 3.67 (baik).

Aktivitas belajar peserta didik juga meningkat, dimana pada siklus pertama sebesar 3,48 (aktif) dan siklus kedua sebesar 3,70 (aktif). Penggunaan LKPD sangat membantu guru dalam meningkatkan aktivitas pembelajaran.

Penelitian tindakan kelas dengan pola LS ini dilaksanakan dalam 2 siklus sebagai upaya untuk meningkatkan hasil belajar kognitif Fisika peserta didik pada pokok bahasan besaran dan satuan tahun pelajaran 2017/2018 di SMAN 3 Mataram melalui penerapan model ekspositori berbantuan advace organizer. Pada siklus I diperoleh nilai rata-rata kelas sebesar 67,87 dengan nilai kriteria ketuntasan minimal individu sebesar 70 dan ketuntasan klasikal 
sebesar 70\%. Berdasarkan hasil belajar peserta didik tersebut, menunjukkan bahwa hasil belajar peserta didik belum mencapai indikator keberhasilan dan belum sepenuhnya sintaks model ekspositori berbantuan advace organizer, indikator keberhasilan yaitu jika ketuntasan klasikal lebih dari $85 \%$ dan mendapat nilai di atas kriteria ketuntasan minimal 70, sehingga penelitian dilanjutkan ke siklus II.

Pada siklus I, masih terdapat kendala selama proses pembelajaran berlangsung. Kendala yang dihadapi selama menerapkan model ekspositori berbantuan advace organizer yaitu secara keseluruhan guru mengalami kesulitan dalam pengaturan waktu secara tepat karena adanya pergerakan peserta didik dalam kegiatan pengayaan dan remidial. Dengan demikian pada siklus ini banyak kegiatan yang kurang efektif karena kurangnya waktu yang tersedia. Selain itu, peserta didik juga belum memahami sintaks strategi ini dengan benar sehingga beberapa langkah kegiatan tidak terlaksana. Hal ini menyebabkan hasil yang diperoleh tidak optimal. Kekurangankekurangan juga disebabkan oleh faktor kesiapan peserta didik dan guru yang masih kaku dan dalam beberapa kegiatan peserta didik masih membuat keributan.

Berdasarkan kendala-kendala dan kekurangan-kekurangan pada siklus I, maka dilakukan tindakan perbaikan pembelajaran yang diterapkan pada siklus II. Perbaikanperbaikan yang dilakukan antara lain pengalokasian waktu dengan tepat, kegiatan formatif hampir sepenuhnya dilakukan di luar jam pelajaran (pada saat jam istirahat). Pada jam pelajaran tes formatif tidak bisa dilaksanakan karena keterbatasan waktu. Bahan formatif, prasyarat, remidial dan pengayaan dikurangi. Bahan pelajaran yang disampaikan lebih terarah sehingga waktu dapat dimanfaatkan secara maksimal. Pada siklus I sintaks belum terlaksana sepenuhnya karena kondisi peserta didik yang kurang kondusif. Hal ini diperbaiki dengan cara sebelum memulai pembelajaran sintaks kegiatan dijelaskan terlebih dahulu, dari yang umum sampai ke bagian yang paling khusus. Sintaks ditulis dan dijabarkan secara eksplisit. Dengan demikian peserta didik dapat memahami sintaks proses pembelajaran yang akan dipelajari. Untuk mengefektifkan semua proses pembelajaran peserta didik disiapkan terlebih dahulu. Peserta didik yang masih ribut atau bermain diberikan reinforcement berupa sanksi atau ditunjuk secara acak untuk mengerjakan tugas. Dengan perbaikan-perbaikan tersebut diharapkan diperoleh hasil yang sesuai dengan tujuan yang diharapkan.

Pada siklus II diperoleh data hasil belajar kognitif peserta didik mengalami peningkatan baik nilai rata-rata kelas maupun ketuntasan klasikal. Nilai rata-rata kelas diperoleh sebesar 79,39 sedangkan untuk ketuntasan klasikal diperoleh sebesar 91\%. Hasil tersebut memperlihatkan bahwa pembelajaran telah memenuhi indikator keberhasilan. Artinya bahwa nilai rata-rata kelas meningkat dari 67,87 menjadi 79,39 (dari 23 orang peserta didik menjadi 30 orang peserta didik yang mencapai kriteria ketuntasan minimal sebesar 70) dan nilai ketuntasan klasikal juga telah mencapai $85 \%$.

Melalui penerapan model ekspositori berbantuan $A O$ yang telah dilakukan dalam penelitian ini dapat memberi manfaat positif bagi peserta didik dan guru. Dengan strategi ini peserta didik lebih diperhatikan secara individu tanpa mengabaikan kemampuan kelompok. Kemampuan kelompok tidak akan maksimal tanpa adanya kemampuan personal. Strategi ini juga bermanfaat untuk meningkatkan produktivitas hasil belajar peserta didik, sehingga peserta didik dapat menguasai bahan pelajaran secara tuntas, menyeluruh dan utuh. Pelaksanaannya dilaksanakan secara bertahap dengan unitunit pembelajaran yang lebih kecil dan 
dengan evaluasi secara terus menerus (continous evaluation). Kegiatan evaluasi yang terus menerus akan menyebabkan peserta didik lebih terlatih dan terampil dalam menyelesaikan permasalahan sendiri. Dengan demikian peserta didik akan memperoleh hasil yang lebih maksimal. Hal inilah yang diharapkan dapat memotivasi dan menjadi dasar untuk menumbuhkan kepercayaan diri peserta didik dalam menyelesaikan pokok bahasan yang lebih kompleks. Dengan hasil maksimal secara spontanitas peserta didik akan belajar lebih giat lagi. Secara tidak langsung peserta didik sudah mendapatkan dorongan psikologis berupa hasil yang memuaskan dirinya. Hal ini merupakan modal awal yang sangat tepat untuk memulai pokok bahasan yang lebih kompleks. Dalam kegiatan pembelajaran peserta didik yang tidak bisa dibantu oleh guru jika masih malu maka peserta didik tersebut masih bisa bertanya pada teman (tutor sebaya) sehingga tidak ada kata tidak bisa atau gagal dalam belajar. Hasil pembelajaran dengan peserta didik sebaya dipandang lebih baik bagi anak yang mempunyai rasa takut atau enggan terhadap gurunya. Peserta didik dapat dengan mudah menguasai isi pembelajaran karena didiskusikan terlebih dahulu bersama guru sebelum memulai kegiatan pembelajaran, dengan demikian peserta didik sudah memiliki kemampuan awal mengenai materi yang diajarkan. Selain itu, Peserta didik menjadi terbiasa dalam menganalisis soalsoal yang berkaitan dengan ranah kognitif karena evaluasi terus menerus dilakukan. Dalam penelitian ini juga dilaksanakan dengan berbagai metode untuk memperoleh hasil yang maksimal. Meskipun yang diteliti hanyalah kemampuan kognitif namun kegiatan psikomotorik melalui kegiatan eksperimental dan ranah afektif melalui observasi juga diperlukan untuk menunjang hasil belajar kognitif yang merupakan tujuan utama penelitian ini. Manfaat bagi guru antara lain, dapat menerima umpan balik dengan cepat dan segera melalui evaluasi secara terus menerus. Evaluasi ini juga dapat berfungsi sebagai alat diagnosa kemampuan peserta didik dan keberhasilan program yang telah dilakukan.

Berdasarkan hasil penelitian dan pembahasan di atas, diketahui bahwa hasil belajar kognitif belajar peserta didik mengalami peningkatan dari siklus I ke siklus II. Dengan demikian, penerapan model ekspositori berbantuan advace organizer dengan pola lesson study dapat meningkatkan hasil belajar kognitif fisika peserta didik kelas $\mathrm{X}$ MIA3 SMAN 3 Mataram Tahun Pelajaran 2017/2018 pada pokok bahasan besaran dan satuan dan model ekspositori berbantuan advace organizer dapat digunakan sebagai alternatif pembelajaran untuk meningkatkan hasil belajar fisika dan aktivitas belajar fisika peserta didik.

Hasil penelitian ini sejalan dengan penelitian Harjono (2011), Nopiani, dkk (2017), Hamdanillah, dkk (2017) yang menyatakan bahwa pemberian advance organizer dalam berbagai bentuk dalam pembelajaran fisika dapat meningkatkan hasil belajar fisika. Pemberian $A O$ mampu menghubungkan pengetahuan awal dengan pengetahuan yang akan dipelajari sehingga informasi yang diperoleh menjadi bermakna. Informasi bermakna diperoleh juga bila $A O$ mampu memperkuat struktur kognitif dan menambah daya ingat (retensi) (Huda, 2013). Mika, dkk (2014) menyatakan bahwa $A O$ mampu meningkatkan minat belajar dan hasil belajar kalor siswa kelas VII dan Prelia, dkk, 2017 menyebutkan pula bahwa $A O$ mampu memfasilitasi peserta ddik dalam meningkatkan kemampuan pemecahan masalah fisika. Secara spesifik, Hasbiyalloh, dkk (2017) menyebutkan bahwa model pembelajaran ekspositori berbantuan $A O$ memberikan pengaruh positif terhadap peningkatan hasil belajar fisika pesetta 
didik. Dengan demikian hasil penelitian ini memperkuat teori dan penelitian-penelitian yang mendahului bahwa pemberian $A O$ mampu meningkatkan hasil belajar kognitif karena $A O$ mampu menjembatani konsepkonsep untuk memperkuat struktur kognitif dan belajar bermakna.

\section{PENUTUP}

Berdasarkan hasil penelitian dan pembahasan yang telah dipaparkan dapat disimpulkan bahwa penerapan model pembelajaran ekspositori dengan bantuan advance organizer dengan pola lesson study mampu meningkatkan aktivitas dan hasil belajar fisika peserta didik kelas X SMA 3 Kota Mataram.

\section{UCAPAN TERIMA KASIH}

Tim peneliti mengucapkan terima kasih yang sebesar-besar kepada Tim Penelitian Dana PNBP 2017 yang telah melibatkan kami dalam penelitiannya, membimbing dan mengajarkan banyak hal, serta memfasilitasi semua proses hingga publikasi ilmiah bersama.

\section{REFERENSI}

Amanah, P. D., Harjono, A \& Gunada, I. W. 2017. Kemampuan Pemecahan Masalah Dalam Fisika Dengan Pembelajaran Generatif Berbantuan Scaffolding dan Advance Organizer. Jurnal Pendidikan Fisika dan Teknologi. 3(1), 84-91.

Arends, R. I. 2007. Learning to Teach. New York: McGraw Hill Company, Inc.

Ausubel, D.P. 1960. The Use of Advance Organizers in the Learning and Retention of Meaningful Verbal Material. Journal of Educational Psychology. 51.

Ausubel, D.P. 1963. Cognitive Structure and the Facilitation of Meaningful Verbal Learning. Journal of Teacher Education, 14
Ausubel, D.P. 1978. The defense of Advance Organizers: A reply to the Critics. Review of Educational Research. 48(2): 251-257.

Diptoadi, V.L. 1990. Pengaruh Cara Penyampaian Bacaan dengan Menggunakan Advance Organizer dan Daftar Kata Pokok Terhadap Perolehan Membaca Mahasiswa Jurusan Bahasa Inggris yang Memiliki Karakter Berbeda. Desertasi tidak diterbitkan. Malang: Program Pascasarjana IKIP Malang.

Downing, A. 1994. An Investigation of the Advance Organizer Theory as an Effective Teaching Model. Paper presented at the Annual Meeting of Australian Teacher Education Association $\left(24^{\text {th }}\right), \quad$ Queensland Australia. July 3-6.

Hamdanillah, N, Harjono, A, \& Susilawati, S. 2017. Pengaruh Model Pembelajaran Advance Organizer Menggunakan Video Pembelajaran Terhadap Hasil Belajar Fisika Peserta Didik Kelas XI, Jurnal Pendidikan Fisika dan Teknologi. 3(2), 120-127.

Harjono, A. 2011. Perbedaan Strategi Pembelajaran dan Pemberian Advance Organizer Pengaruhnya Terhadap Hasil Belajar Fisika Siswa Kelas X. Jurnal Pijar Matematika Ilmu Pengetahuan Alam. 7(1), 13-17.

Hasbiyalloh, A. S., Harjono, A, \& Verawati, N.N.S.P. 2017. Pengaruh Model Pembelajaran Ekspositori Berbantuan Scaffolding dan Advance Organizer Terhadap Hasil Belajar Fisika Peserta Didik Kelas X. Jurnal Pendidikan Fisika dan Teknologi. 3(2), 173-180.

Heinich, R., Molenda, M., Russell, D.J. \& Smaldino, E. 2002. Instructional Media and Technology for Learning. (Seventh edition). New Jersey: Prentice Hall, Inc. 
Huda, M. 2013. Model-Model Pengajaran dan Pembelajaran. Yogyakarta: Pustaka Pelajar.

Hunter, M. 1984. Instructional Theory into Practice. Virginia: Polytechnics Institute.

Jacobsen, D., Eggen, P. \& Kauchack, D. 1989. Methods for Teaching: A Skill Approach. Colombus, Ohio: Merrill Publishing Company.

Joyce, B., Weil, M. \& Calhoun, E. 2000. Models of Teaching. (6 $\left.{ }^{\text {th }} \mathrm{ed}\right) . \mathrm{NJ}$ : Allyn \& Bacon.

Lewis, C., 2002, Lesson Study: A Handbook of Teacher-Led Instructional Change, Philadelphia, PA: Research for BetterSchools, Inc.

Mayer, R.E. 2003. Learning and Instruction. New Jersey: Pearson Education, Inc.

Medsker, K. L. \& Holdsworth, K M. 2001. Model and Strategies for Training Design. International Society for Performance Improvement: Silver Spring.

Mika, J, Xainuddin, Z, \& An'nur, S. 2014. Penerapan Model Pembelajaran Advance Organizer (AO) untuk Meningkatkan Hasil Belajar Siswa. Berkala Ilmiah Pendidikan Fisika. 2(3), 222-233.

Novak, J.D. \& Canas, A. J. 2008. The Theory Underlying Concept Maps and How to Construct Them. Technical Report IHMC Cmap Tools 2006-01 Rev 01-2008, Florida: Cornell University.

Nopiani, R, Harjono, A, \& Hikmawati. 2017. Pengaruh Model Pembelajaran Advance Organizer Berbantuan Peta Konsep Terhadap Hasil Belajar Fisika Siswa SMA Negeri 1 Lingsar, Jurnal Pendidikan Fisika dan Teknologi. 3(2), 137-145.

Reigeluth, C. M. \& Stein, F.S. 1983. Instructional Design Theories and Model: An overview of their current status. New Jersey: Lawrence Erlbaum Associates, Publisher.

Romiszowski, A. J. 1984. Producing Instructional System: Lesson Planning for Individualized and Group Learning Activities. London: Kogan Page.

Sagala, S. 2006. Konsep dan Makna Pembelajaran. Bandung: Penerbit Alfabeta.

Widarto.2014. Makalah Seminar Nasional Hasil Implementasi Lesson Study dalam Program STOLS for ITTEP. Jakarta. 